\title{
Modified trapdoor procedures using autogenous tricortical iliac graft without preserving the broken cartilage to treat osteonecrosis of the femoral head: A Prospective Cohort Study With Historical Controls
}

qi Cheng

xuzhou cancer hospital

fengchao zhao ( $D$ 1648292420@qq.com )

Zhejiang University School of Medicine First Affiliated Hospital

Shizhuang Xu

Xuzhou Medical University

\section{Li Zheng}

Xuzhou Medical University

\section{Xin Zheng}

Xuzhou Medical University

\section{Research article}

Keywords: osteonecrosis, hip, bone graft, surgical procedure, cartilage, outcome

Posted Date: February 17th, 2020

DOI: https://doi.org/10.21203/rs.2.22986/v1

License: (a) (1) This work is licensed under a Creative Commons Attribution 4.0 International License.

Read Full License 


\section{Abstract}

Background The aim of the present study was to investigate clinical and radiological outcomes of autologous tricortical iliac graft through a window created at the femoral head, without suturing the opened articular cartilage to treat osteonecrosis of the femoral head (ONFH), called modified trapdoor procedures.

Methods A total of 59 consecutive patients (67 hips; 36 males and 23 females) with ONFH were included in this study, which was conducted during the period from April 2009 to March 2012. Patient age ranged from 27 to 46 years old, with mean age of 36.3 years. Harris hip scores (HHS) were used to evaluate hip function pre- and postoperatively. Anteroposterior and frog-position X-rays and magnetic resonance imaging (MRI) were conducted to evaluate lesion location, size, and ARCO stage. Clinical failure was defined as score $<80$ points or treatment by total hip arthroplasty(THA). Radiographic failure was defined as a $>3 \mathrm{~mm}$ of collapse in the hip. This group was retrospectively matched according to the ARCO stage, extent, location, etiology of the lesion, average age, gender, and preoperative Harris hip score to a group of 59 patients (67 hips) who underwent the"light bulb"approach during March 2007 to April 2009.

Results Mean follow-up was $91.2 \pm 13.6$ months (range, $75-115$ months). Mean HHS was $91.3 \pm 4.5$, compared with $83.1 \pm 4.5$ in the "light bulb" cohort at the 6 years follow-up examination $(P<0.001)$. At the 6 years follow-up, for modified trapdoor procedures, five hips (8.5\%) were classified as clinical failure, and 3 hips underwent total hip arthroplasty; Seven hips were classified as $(10.4 \%)$ radiographic failure.The clinical and radiographic failure of the hips treated with the modified trapdoor procedure was significantly lower than that of the hips treated with the "light bulb" procedure $(p<0.05)$. Survival of the joint was not significantly related to the location of the femoral head lesion between two groups, but there was better clinical and radiographic results in modified trapdoor procedures with Size-C and the ARCO stage III.

Conclusion The study demonstrated superior medterm clinical results in ONFH with the use of autologous tricortical iliac block graft through a femoral head window, without suturing the opened articular cartilage. The results of this femoral head-preserving procedure in patients with postcollapse osteonecrosis and large lesion are superior to those of the "light bulb" procedure treatment.

\section{Introduction}

Untreated osteonecrosis of the femoral head (ONFH) is associated with poor outcomes because of subchondral collapse and subsequent osteoarthrosis ${ }^{[1-5]}$. Research in various study populations has shown that collapse of the femoral head occurs in $44-79 \%$ of cases. The time interval between collapse and the ONFH diagnosis is usually less than 2 years ${ }^{[3-5]}$. Unfortunately, this disease usually affects relatively young and active patients. Among cases associated with corticosteroid use, mean age is 35 years. Among cases associated with alcohol abuse, mean age is 41 years. Among cases associated with trauma, mean age is 41 years. Among cases of idiopathic etiology, mean age is 40 years ${ }^{[6]}$. Total hip arthroplasty (THA) is often performed to treat this intractable disease (88\%), with good short-term results 
[5]. Previous studies showed that long-term outcomes for THA in the treatment of ONFH were inferior to those achieved for THA in the treatment of osteoarthritis ${ }^{[7,8]}$. Although arthroplasty prosthesis designs and procedures have improved over recent decades, patients in this group remain likely to undergo multiple revisions because of high levels of physical activity and long life expectancy. Progressive stem loosening and central migration of the prosthesis have been reported. Such complications require revision surgery. Revision surgery is often more difficult, costly, and less effective than the original surgery, sometimes resulting in complications and/or mortality ${ }^{[9-11]}$.

Therefore, the need for joint-preserving strategies continues to increase ${ }^{[5]}$. Multiple treatment modalities have been developed to avoid femoral head collapse and subsequent destruction of the hip joint or deferral of THA. The treatment procedures performed most commonly include core decompression, osteotomy, non-vascularized or vascularized bone graft, enriched bone substitutes, transplantation of a tantalum rod, and autologous bone marrow stem cell implantation. All of these procedures aim to promote bone regeneration and/or provide mechanical support ${ }^{[10-26]}$. However, none of these treatment modalities have been found to be universally successful. The reasons for the failure of these treatments are that dead bone cannot be replaced by viable bone, subchondral bone does not have sufficient mechanical support, and subsequent progression of osteoarthritis ${ }^{[27-31]}$.

Most of head-preserving procedure tried to maintain the articular cartilage over the necrotic zone, such as trapdoor procedure, lightbulb procedure, Phemister technique, implantation of tantalum, etc ${ }^{[5,11-31]}$. Actually the necrotic subchondral bone is hard to heal with bone graft, marked collapsed is still observed during conversion to $\mathrm{THA}^{[18]}$. The segmented collapsed cartilage may have combined with subchondral bone to become a floating body, resulting in pain. More and more studies showed that if the mechanical was stable, the hips could maintain no symptom or a slight discomfort. Partly defect of joint cartilage does not associated with poor clinical results ${ }^{[32,33]}$. In a minimum 5 years follow-up, femoral head with chondral lesion does not portend a worse clinical outcome ${ }^{[34]}$. All of these findings indicate that mechanical failure, rather than cartilage degeneration, is the main cause of symptom in ONFH without arthritis. So we modified the trapdoor procedure by grafting an autologous tricortical iliac bone block through a window in the femoral head without preserving the articular cartilage. We describe the principles and surgical techniques used to perform the procedure and compare the results achieved with the lightbulb procedure.

\section{Methods}

\section{Patients}

Approval was obtained from the institutional review board and written informed consent was obtained from each patient. We prospectively investigated 61 consecutive ONFH cases (69 hips) from patients who underwent bone grafting through a window in the femoral head, during the period from April 2009 to March 2012. The diagnostic criteria for ONFH as identified with magnetic resonance imaging (MRI) were 
a low signal band in the T1-weighted image and a high signal band in the corresponding STIR sequence [35]. The inclusion criteria were: (1) consent to participate in the present study with at least 6 years of follow-up; (2) age $\leq 50$ years; (3) no joint-space narrowing; (4) discomfort (pain in the hip, groin, buttock, or knee) that interfered with daily activity; (5) lack of a neurological disorder that could affect the source of the patient's complaint; (6) no active connective tissue disease (e.g., rheumatoid arthritis, systemic lupus erythematosus). Two patients (2 hips) were excluded from the study because of loss to follow-up. Ultimately, 59 patients ( 23 women and 36 men, 67 hips) were available for review. Among these patients, age ranged from 27 to 46 years old, with mean age of $36.3 \pm 5.3$ years. The etiology of osteonecrosis was as follows: use of corticosteroids in 20 hips, alcohol abuse in 37 hips, and idiopathic etiology in 10 hips.

All hips were graded according to guidelines provided by the Association Research Circulation Osseous $(\text { ARCO })^{[36]}$. Lesions that occupied $<15 \%$ of the femoral head were classified as Size A; lesions that occupied $15-30 \%$ of the femoral head were classified as Size B; lesions that occupied $>30 \%$ of the femoral head were classified as $\mathrm{C}^{[36]}$. Location of the lesion on coronal midsection T1-weighted images was classified as one of four types, according to criteria proposed by Sugano et al. ${ }^{[37]}$. Type A account for one-third or less of lesions affecting the medial weight-bearing portion. Type B account for two-thirds or less. Type $\mathrm{C} 1$ account for more than two-thirds without extending laterally to the acetabular edge. Type $\mathrm{C} 2$ account for more than two thirds and extend laterally to the acetabular edge.

63 patients (72 hips), who had undergone auto-iliac bone-grafting through a window at the femoral headneck junction known as the"light bulb"approach for the treatment of osteonecrosis of the femoral head from March 2007 to April 2009, were retrospectively matched to 59 patients (67 hips) who underwent bone grafting through a window in the femoral head. The matching was based on the stage, extent, location, etiology of the lesion, average age, gender, and preoperative Harris hip score (Table I).

All cases were followed at 3, 6, and 12 months, then annually. Harris hip scores (HHS) and ARCO stage were recorded at each follow-up examination. Anteroposterior and frog-position X-rays, CT as well as MRI scans were obtained.

HHS was used to evaluate clinical outcomes. Excellent, good, fair and poor results were defined as $>90$, $80-89,70-79$, and $<70$, respectively. Scores $<80$ points or patients who had undergone THA were classified as examples of clinical failure. Clinical success was defined as a score $\geq 80$ points.

Each patient was also radiographically evaluated in terms of the progression in terms of ARCO stage. Hips have $>3 \mathrm{~mm}$ of collapse or progress to ARCO $\otimes$ defined as radiographical failure ${ }^{[26]}$.

\section{Surgical technique}

Modified trapdoor procedures were performed by Fengchao Zhao et al. The patient was put in a supine position, and the ilium was elevated $\left(10-15^{\circ}\right)$ by placing a sandbag under the buttock. The procedure was performed using an anterior minimally invasive approach, with the patient under epidural or general anesthesia. An anterior straight incision, about $6 \mathrm{~cm}$ in length, was made about $1 \mathrm{~cm}$ distal and posterior 
to the anterior superior iliac spine. We exposed the hip joint capsule through the interval between the rectus femoris and the tensor fascia lata. The anterior part of the superficial aponeurosis was used to prevent damage to the lateral femoral cutaneous nerve. The femoral head was revealed by dissecting the joint capsule. MRI and computed tomography (CT) were performed preoperatively to localize the necrotic lesion and to determine the width of the tricortical bone block harvested from the iliac crest. The surgeon then created a window-like incision and used a scalpel to prepare a bone groove, extending from the head-neck junction to the acetabular rim, along the shaft of the femoral neck in the necrotic region of the femoral head. Necrotic bone was resected using osteotomes and power burrs, and curettage was performed until a bleeding surface was observed (Fig. 1). Ipsilateral autologous tricortical iliac bone was trimmed into the shape, which was consistent with the length of the window and the depth of the necrosis. Finally, the iliac bone block and a small cancellous bone graft were filled tightly by hammering at the surgical site. This restored the prototype of the articular surface. The screws fixed bone graft through the iliac bone to the femoral head and the screw heads were hidden in the bone. The resected segment of articular cartilage was no longer covered. The range of joint motion was measured, as well as the stability of the labrum. Any cam impingement was corrected. The joint capsule was then closed. The procedure was completed with fascial, subcutaneous, and skin stitches. A drain was left in place for $24 \mathrm{~h}$ (Fig. 2).

Patients started active range-of-motion exercises, as per their pain tolerance. Weight-bearing was forbidden in the first 3 months. At that point, patients were allowed to begin partial weight-bearing. Full weight-bearing was begun at least 4 months postoperatively, depending on the extent of clinical and radiological union.

\section{Statistical analysis}

Continuous data are reported as means \pm standard deviation. A paired t-test was used to compare changes in HHS. We used Pearson's chi-squared or Fisher's exact test to evaluate the relationship between variables and results. All analyses were performed with SPSS statistical software package, ver. 19.0 (SPSS, Inc., Chicago, Illinois, USA). P 0.05 was considered to be statistically significant.

\section{Results}

In total, 59 patients (67 hips) were followed for a minimum of 6 years (mean, $91.2 \pm 13.6$ months; range, 75-115 months). Average operation time (unilateral hip) was $50.5 \pm 10.7$ minutes, with blood loss of $95.2 \pm 22.8 \mathrm{ml}$.

The clinical and radiographic results are shown in Table II. Mean HHS was $91.3 \pm 4.5$, compared with $83.1 \pm 4.5$ in the "light bulb" cohort at the 6 years follow-up examination $(P<0.001)$. The clinical results were good-to-excellent in 62 hips (92.5\%), fair in 2 hips, and poor in 3 hips. All 5 hips progressed to collapse; 3 hips underwent further THA. 
At the 6 years follow-up examination, 7 hips with modified trapdoor procedures, had failed, according to radiographic evaluation criteria. Five hips had fair or poor clinical results. Of the 72 hips with the lightbulb procedure, eighteen had radiographic signs of progression and fifteen of them had fair or poor clinical results. The clinical and radiographic failure of the hips treated with the modified trapdoor procedure was significantly lower than that of the hips treated with the "light bulb" procedure $(p<0.05)$.

When all hips in the two groups were compared at the time of the final follow-up. We observed no significant difference between groups in terms of location $(p>0.05)$. We found collapsed hips (ARCO stage III) were more prone to clinical and radiographic failure in the "light bulb" group $(p=0.041,0.014)$. Furthermore, the rates of fair or poor clinical results and collapse for size $C$ were found to be significantly lower in the group treated with the modified trapdoor procedure $(p=0.023,0.038)$.

There were no significant complications (e.g., fracture, joint infection, deep venous thrombosis) in any patient who underwent this procedure. Two hips with wound-related issues healed after the wounds were dressed properly.

\section{Discussion}

The rationale for head-preserving procedures is the desire to provide sufficient and long-lasting support to necrotic subchondral bone and cartilage ${ }^{[38]}$, in order to prevent collapse and subsequent osteoarthrosis of the joint. A tantalum rod was used to provide direct mechanical support ${ }^{[16]}$; a bone graft was aimed to replace dead bone with viable bone ${ }^{[12-14]}$. Various types of stem cells and/or biofactors were used to facilitate bone formation and remodeling, alone or in combination with other methods ${ }^{[15,19]}$. Vascularized bone graft is deemed have better effect than nonvascularized bone graft, is technically demanding. Nonvascularized bone graft procedures are currently the most popular methods for preserving the necrotic head and/or deferring THA. Three surgical techniques are common used: (1) the Phemister technique: grafting via a core decompression tract from the greater trochanteric area; (2) "lightbulb" procedure: grafting through a femoral neck or femoral head-neck junction window; (3) trapdoor procedure: grafting through a femoral head window.

Keizer et al. ${ }^{[21]}$ described a cohort of cases that underwent autogenous cancellous bone grafting via a core tract (Phemister technique), after a mean of 7 years of follow-up; 34 of 78 hips (44\%) required additional surgery. This procedure is now out of favor, as the necrotic bone was not sufficiently debrided, resulting in insufficient solid support for subchondral bone ${ }^{[17,20]}$. In 1998, Mont et al. ${ }^{[18]}$ introduced use of the trapdoor procedure, which involves creating a window at the femoral head. In that study, 20 of 24 Ficat stage III hips (83\%) had good or excellent outcomes. This procedure involves disrupting the integrity of the femoral head cartilage, which has been shown to prevent healing. More and more clinicians are choosing to perform bone grafting through a femoral neck or head-neck junction window without disrupting the weight-bearing cartilage (lightbulb procedure). Rosenwasser et al. ${ }^{[23]}$ chiseled out a femoral head-neck junction window and observed a success rate of $81 \%$ at 12 years. 
All of these procedures tried to maintain the articular cartilage over the necrotic zone. In our study, the clinical survival rate of the procedure without suturing the opened articular cartilage was $92.5 \%$ for a minimum of six years, significantly superior to lightbulb procedure. The lightbulb procedure did not damage the articular cartilage. However, it encountered two difficult technical problems. First, it is difficult to completely remove necrotic bone. Actually the necrotic subchondral bone is hard to heal with bone graft, marked collapsed is still observed during conversion to THA ${ }^{[18,27-31]}$. Second, we could not perform perfect bone grafting to fill the canal. even if a sophisticated operation to restore the spherical shape of the femoral head is performed, some mild joint incongruence would be present, and it would be impossible to maintain the sphericity without collapse for longer periods. The collapsed cartilage and subchondral bone may serve as floating body and is harm for health. With partly cartilage defect, the function of hip was still well. Femoral head with part chondral lesion detected during arthroscopic surgery still functioned well with minimum 5 years follow-up ${ }^{[34]}$. These findings indicate that mechanical failure, rather than cartilage degeneration, is the main cause of pain. So we modified the trapdoor procedure. After thorough debridement, an autologous tricortical iliac block graft combined with morselized bone was implanted. Broken cartilage and necrotic subchondral bone was no longer replanted. Compared with previous studies ${ }^{[12-26]}$, this report includes superior results. The rate of clinical success (good or excellent outcome) was $92.5 \%$ for 67 hips.

Larger lesions and more advanced linear collapse increase the relative risk of failure. Wang et al. ${ }^{[22]}$ in a retrospective study of 110 patients, who underwent 138 light bulb procedures with a mean follow-up of 25.37 months, demonstrated that "light bulb" technique should not be performed once if subchondral collapse is present. Similarly, Sotereanos et al. ${ }^{[39]}$ showed that the probability of conversion to total hip arthroplasty within an average of 5.5 years after Autogenous Grafts was 38\% for stages III and IV hips. The rate of collapse for modified trapdoor procedures was only $18.2 \%$ or $9.5 \%$ among ONFH hips of ARCO III or size C. When compared with light bulb procedures, modified trapdoor procedures is also a worthwhile procedure in patients with postcollapse osteonecrosis. It doesn't care about the cartilage lesion of ARCO III and thoroughly remove dead bone tissue for size C. Autogenous tricortical iliac provides sufficient support, filles effectively necrotic cavity, and demonstrates incorporation of the graft to the recipient bone of the femoral head.

The first advantage of our technique, compared with the traditional trapdoor procedure, was that a tricortical iliac block graft fixed with one or two screws can more easily heal with host bone and provide good structural support ${ }^{[18,32]}$. The autogenous iliac crest transplantation is an effective treatment. However, there is a risk of bone flap loosening. Therefore, screw fixation is needed to increase the stability of the bone flap. The second advantage was our procedure did not involve suturing the opened articular cartilage, so there were no issues related to necrotic subchondral bone healing with graft bone or cartilage-cartilage interface healing. Floating cartilage slices, just as osteochondritis dissecans, may be another reason for unsatisfactory results. Thirdly, use of the anterior approach without dislocation of the hip, results in less damage to posterior structures, with excellent exposure and preservation of the blood supply $[40,41]$. Finally, this procedure has the advantages of being minimally invasive, technically simple, 
short in operative duration, associated with fewer complications, and associated with no adverse effect on the procedure of late arthroplasty.

\section{Conclusion}

The results of the procedure suggests that the modified trapdoor procedure is associated with better clinical and radiographic results than the lightbulb procedure in femoral head osteonecrosis, particularly those with ARCO Stage-III or Size-C disease. Finally, inpatients with postcollapse osteonecrosis, which always destroys articular cartilage and damages bone beneath cartilage, the procedure appears to delay hip arthroplasty in the majority of patients, and it may eliminate the need for eventual arthroplasty in many of them.

\section{Declarations}

\section{Availability of data and materials}

We do not wish to share our data, because some of patients data regarding individual privacy, and according to the policy of our hospital, the data could not be shared to others without permission.

\section{Acknowledgements}

Not applicable.

\section{Authors'contributions}

QC drafted the manuscript. FCZ ,SZX, LZ and XZ performed data collection and data analysis. QC and FCZ conceived of the study, participated in the design of the study, performed data interpretation, and participated in coordination. All authors read and approved the final manuscript.

\section{Ethics approval and consent to participate}

Not applicable.

\section{Consent for publication}

Not applicable.

\section{Competing interests}

The authors declare that they have no competing interests.

\section{Abbreviations}

ONFH: osteonecrosis of the femoral head; THA: total hip arthroplasty; CT: computed tomography 


\section{References}

1. Sonoda K, Motomura G, Kawanami S, Takayama Y, Honda H, Yamamoto T, et al. Degeneration of articular cartilage in osteonecrosis of the femoral head begins at the necrotic region after collapse: a preliminary study using T1 rho MRI. Skeletal Radiol. 2017; 46: 463-7.

2. Cao H, Guan H, Lai Y, Qin L, Wang X. Review of various treatment options and potential therapies for osteonecrosis of the femoral head. J Orthop Translat. 2016; 4: 57-70.

3. Mont MA, Jones LC, Hungerford DS. Nontraumatic osteonecrosis of the femoral head: ten years later. J Bone Joint Surg Am. 2006; 88: 1117-32.『

4. Wakaba Fukushima, Mikihiro Fujioka, Toshikazu Kubo, Akiko Tamakoshi, Masaki Nagai, Yoshio Hirota. Nationwide Epidemiologic Survey of Idiopathic Osteonecrosis of the Femoral Head. Clin Orthop Relat Res. 2010; 468: 2715-24.

5. Johnson AJ, Mont MA, Tsao AK, Jones LC. Treatment of Femoral Head Osteonecrosis in the United States: 16-year Analysis of the Nationwide Inpatient Sample. Clin Orthop Relat Res. 2014; 472: 61723.

6. Zhao FC, Li ZR, Zhang NF. Clinical analysis of osteonecrosis of the femoral head with different

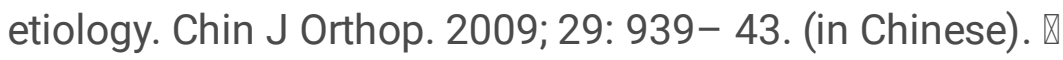

7. Saito S, Saito M, Nishina T, Ohzono K, Ono K. Long-term results of total hip arthroplasty for osteonecrosis of the femoral head. A comparison with osteoarthritis. Clin Orthop Relat Res. 1989; 244:198-27.

8. Fyda TM, Callaghan JJ, Olejniczak J, Johnston RC. Minimum ten-year follow-up of cemented total hip replacement in patients with osteonecrosis of the femoral head. lowa Orthop J. 2002; 22: 8-19. \

9. Johannson HR, Zywiel MG, Marker DR, Jones LC, McGrath MS, Mont MA. Osteonecrosis is not a predictor of poor outcomes in primary total hip arthroplasty: a systematic literature review. Int Orthop. 2011; 35: 465-73.

10. Kubo T, Ueshima K, Saito M, Ishida M, Arai Y, Fujiwara H. Clinical and basic research on steroidinduced osteonecrosis of the femoral head in Japan. J Orthop Sci. 2016; 21: 407-13.

11. Lieberman JR, Engstrom SM, Meneghini RM, SooHoo NF. Which Factors Influence Preservation of the Osteonecrotic Femoral Head? Clin Orthop Relat Res. 2012; 470: 525-34.

12. Sionek A, Czwojdziński A, Kowalczewski J, Okoń T, Marczak D, Sibiński M, et al. Hip osteonecroses treated with calcium sulfate-calcium phosphate bone graft substitute have different results according to the cause of osteonecrosis: alcohol abuse or corticosteroid-induced. Int Orthop. 2018; 42: 1491-8.

13. Bertrand T, Urbaniak JR, Lark RK. Vascularized fibular grafts for avascular necrosis after slipped capital femoral epiphysis: is hip preservation possible? Clin Orthop Relat Res. 2013; 471: 2206-11.

14. Zeng YR, He S, Feng WJ, Li FL, Li J, Jian LY, et al. Vascularised greater trochanter bone graft, combined free iliac flap and impaction bone grafting for osteonecrosis of the femoral head. Int Orthop. 2013; 37: 391-8. 
15. Goodman SB. The biological basis for concentrated iliac crest aspirate to enhance core decompression in the treatment of osteonecrosis. Int Orthop. 2018; 42: 1705-9.

16. Liu YS, Yan L, Zhou SG, Su XY, Cao YC, Wang C, et al. Tantalum rod implantation for femoral head osteonecrosis: survivorship analysis and determination of prognostic factors for total hip arthroplasty. Int Orthop. 2016; 40: 1397-407.

17. Mont MA, Etienne G, Ragland PS. Outcome of nonvascularized bone grafting for osteonecrosis of the femoral head. Clin Orthop Relat Res. 2003; 417: 84-92.

18. Mont MA, Einhorn TA, Sponseller PD, Hungerford DS. The trapdoor procedure using autogenous cortical and cancellous bone grafts for osteonecrosis of the femoral head. J Bone Joint Surg Br. 1998; 80: 56-62.

19. Seyler TM, Marker DR, Ulrich SD, Fatscher T, Mont MA. Nonvascularized Bone Grafting Defers Joint Arthroplasty in Hip Osteonecrosis. Clin Orthop Relat Res. 2008; 466: 1125-32.

20. Pierce TP, Elmallah RK, Jauregui JJ, Poola S, Mont MA, Delanois RE. A current review of nonvascularized bone grafting in osteonecrosis of the femoral head. Curr Rev Musculoskelet Med. 2015; 8: $240-5$.

21. Keizer SB, Kock NB, Dijkstra PD, Taminiau AH, Nelissen RG. Treatment of avascular necrosis of the hip by a non-vascularised cortical graft. J Bone Joint Surg Br. 2006; 88: 460-6. \

22. Wang BL, Sun W, Shi ZC, Zhang NF, Yue DB, Guo WS, et al. Treatment of nontraumatic osteonecrosis of the femoral head using bone impaction grafting through a femoral neck window. Int Orthop. 2010; 34:635-9.

23. Rosenwasser MP, Garino JP, Kiernan HA. Long term follow up of thorough debridement and cancellous cone grafting of the femoral head for avascular necrosis. Clin Orthop Relat Res. 1994; 306: 17-27.

24. Gagala J, Tarczyńska M, Gawęda K. Clinical and radiological outcomes of treatment of avascular necrosis of the femoral head using autologous osteochondral transfer (mosaicplasty). Preliminary report. Int Orthop. 2013; 37: 1239-44.

25. Samy AM. Management of osteonecrosis of the femoral head: A novel technique. Indian J Orthop. 2016; 50: 359-65.

26. Yoo MC, Kim KII, Hahn CS, Parvizi J. Long-term Followup of Vascularized Fibular Grafting for Femoral Head Necrosis. Clin Orthop Relat Res. 2008; 466: 1133-40

27. 27.González Della Valle A, Bates J, Di Carlo E, Salvati EA. Failure of free vascularized fibular graft for osteonecrosis of the femoral head: a histopathologic study of 6 cases. J Arthroplasty. 2005; 20:3316.

28. Meloni MC, Hoedemaeker WR, Fornasier V. Failed vascularized fibular graft in treatment of osteonecrosis of the femoral head. A histopathological analysis. Joints. 2016; 4: 24-30

29. 29.Tanzer M, Bobyn JD, Krygier JJ, Karabasz D. Histopathologic retrieval analysis of clinically failed porous tantalum osteonecrosis implants. J Bone Joint Surg Am. 2008; 90: 1282-9. 
30. Zhang X, Wang J, Xiao J, Shi ZJ. Early failures of porous tantalum osteonecrosis implants: a case series with retrieval analysis. Int Orthop. 2016;40:1827-34

31. Cheng Q, Tang JL, Gu JJ, Guo KJ, Guo WS, Wang BL, et al. Total hip arthroplasty following failure of tantalum rod implantation for osteonecrosis of the femoral head with 5- to 10-year follow-up. BMC Musculoskelet Disord. 2018; 19: 289.

32. Sen RK, Tripathy SK, Aggarwal S, Tamuk T. Posterior wall reconstruction using iliac crest strut graft in severely comminuted posterior acetabular wall fracture. Int Orthop. 2011, 35: 1223- 8.

33. Zha GC, Sun JY, Chen L , Zheng HM, Wang Q, Jin Y. Late reconstruction of posterior acetabular wall fractures using iliac crest. J Trauma Acute Care Surg. 2012; 72:1386-92.

34. Ashberg L , Close M , Perets I, Chaharbakhshi E, Walsh JP, Domb BG. Do Femoral Head Osteochondral Lesions Predict a Poor Outcome in Hip Arthroscopy Patients? A Matched Control Study with Minimum 5 Year Follow-Up. Orthop J Sports Med. 2017; 35:419-31.

35. Zhao FC, Hu HX, Zheng X, Cang DW, Liu X, Zhang JZ, et al. Clinical analysis of 23 cases of steroidassociated osteonecrosis of the femoral head with normal initial magnetic resonance imaging presentation. Medicine (Baltimore). 2017; 96: e8834.

36. 36. Gardeniers JWM. The ARCO perspective for reaching one uniform staging system of osteonecrosis. In: Scoutens A, Arlet J, Gardeniers JWM, et al, eds. Bone Circulation and Vascularization in Normal and Pathologic Conditions. New York: Plenum. 1993; 375- 80.

37. 37. Sugano N, Atsumi T, Ohzono K, Kubo T, Hotokebuchi T, Takaoka K. The 2001 revised criteria for diagnosis, classification, and staging of idiopathic osteonecrosis of the femoral head. J Orthop Sci. 2002; 7: 601-5. 叉

38. 38. Xie H, Wang B, Tian S, Liu B, Qin K, Zhao D. Retrospective Long-Term Follow-Up Survival Analysis of the Management of Osteonecrosis of the Femoral Head With Pedicled Vascularized Iliac Bone Graft Transfer. J Arthroplasty. 2019; 34:1585-92.

39. Sotereanos DG, Plakseychuk AY, Rubash HE. Free vascularized fibula grafting for the treatment of osteonecrosis of the femoral head. Clin Orthop Relat Res. 1997; 344:243-56.

40. 40. Rego P, Mascarenhas V, Collado D, Coelho A, Barbosa L, Ganz R. Arterial Topographic Anatomy Near the Femoral Head-Neck Perforation with Surgical Relevance. J Bone Joint Surg Am. 2017; 99 : 1213-21.

41. 41. Lazaro LE, Sculco PK, Pardee NC, Klinger CE, Dyke JP, Helfet DL, et al. Assessment of Femoral Head and Head-Neck Junction Perfusion Following Surgical Hip Dislocation Using GadoliniumEnhanced Magnetic Resonance Imaging: A Cadaveric Study. J Bone Joint Surg Am. 2013; 95: e18218.

\section{Tablels}

Table I: Demographic data for the two groups 


\begin{tabular}{|c|c|c|}
\hline Variables & $\begin{array}{l}\text { the modified trapdoor group }(\mathrm{N}= \\
67)\end{array}$ & $\begin{array}{l}\text { the "light bulb"group }(\mathrm{N}= \\
72)\end{array}$ \\
\hline Age $(\mathrm{yr})$ & $36.3 \pm 5.3$ & $38.5 \pm 4.1$ \\
\hline Male:female & $41: 26$ & $43: 29$ \\
\hline $\begin{array}{l}\text { Mean preop. Harris hip score } \\
\text { (points) }\end{array}$ & $67.3 \pm 7.5$ & $68.2 \pm 6.3$ \\
\hline Etiology (no. of hips) & & \\
\hline Alcohol use & 37 & 38 \\
\hline Use of corticosteroids & 20 & 22 \\
\hline idiopathic etiology & 10 & 12 \\
\hline Preoperative stage & & \\
\hline ACRO II & 45 & 46 \\
\hline ARCO III & 22 & 26 \\
\hline Size & & \\
\hline $\bar{B}$ & 25 & 27 \\
\hline $\mathrm{C}$ & 42 & 45 \\
\hline Location & & \\
\hline $\mathrm{B}$ & 12 & 11 \\
\hline $\mathrm{C}-1$ & 29 & 32 \\
\hline $\mathrm{C}-2$ & 26 & 29 \\
\hline
\end{tabular}

Table II. Demographic results of the procedure

\begin{tabular}{|c|c|c|c|c|c|c|}
\hline & \multicolumn{2}{|c|}{ Clinical failure rate } & \multirow{2}{*}{$\begin{array}{l}\mathrm{P} \\
\text { Value }\end{array}$} & \multicolumn{2}{|c|}{ Radiographical failure rate } & \multirow{2}{*}{$\begin{array}{l}\mathrm{P} \\
\text { Value }\end{array}$} \\
\hline & $\begin{array}{l}\text { the experiment } \\
\text { group }\end{array}$ & $\begin{array}{l}\text { The"light bulb } \\
\text { "group }\end{array}$ & & $\begin{array}{l}\text { the experiment } \\
\text { group }\end{array}$ & $\begin{array}{l}\text { The"light bulb } \\
\text { "group }\end{array}$ & \\
\hline $\begin{array}{l}\text { Preoperative } \\
\text { stage }\end{array}$ & & & & & & \\
\hline ARCO II & $1 / 45$ & $3 / 46$ & 0.617 & $2 / 45$ & $3 / 46$ & 1.000 \\
\hline ARCO III & $4 / 22$ & $12 / 26$ & 0.041 & $5 / 22$ & $15 / 26$ & 0.014 \\
\hline Size & & & & & & \\
\hline $\bar{B}$ & $1 / 25$ & $2 / 27$ & 1.000 & $1 / 25$ & $3 / 27$ & 0.611 \\
\hline $\mathrm{C}$ & $4 / 42$ & $13 / 45$ & 0.023 & $6 / 42$ & $15 / 45$ & 0.038 \\
\hline Location & & & & & & \\
\hline $\bar{B}$ & $0 / 12$ & $2 / 11$ & 0.217 & $0 / 12$ & $3 / 11$ & 0.093 \\
\hline $\mathrm{C}-1$ & $1 / 29$ & $4 / 32$ & 0.357 & $2 / 29$ & $5 / 32$ & 0.429 \\
\hline $\mathrm{C}-2$ & $4 / 26$ & $9 / 29$ & 0.173 & $5 / 26$ & $10 / 29$ & 0.205 \\
\hline
\end{tabular}

\section{Figures}




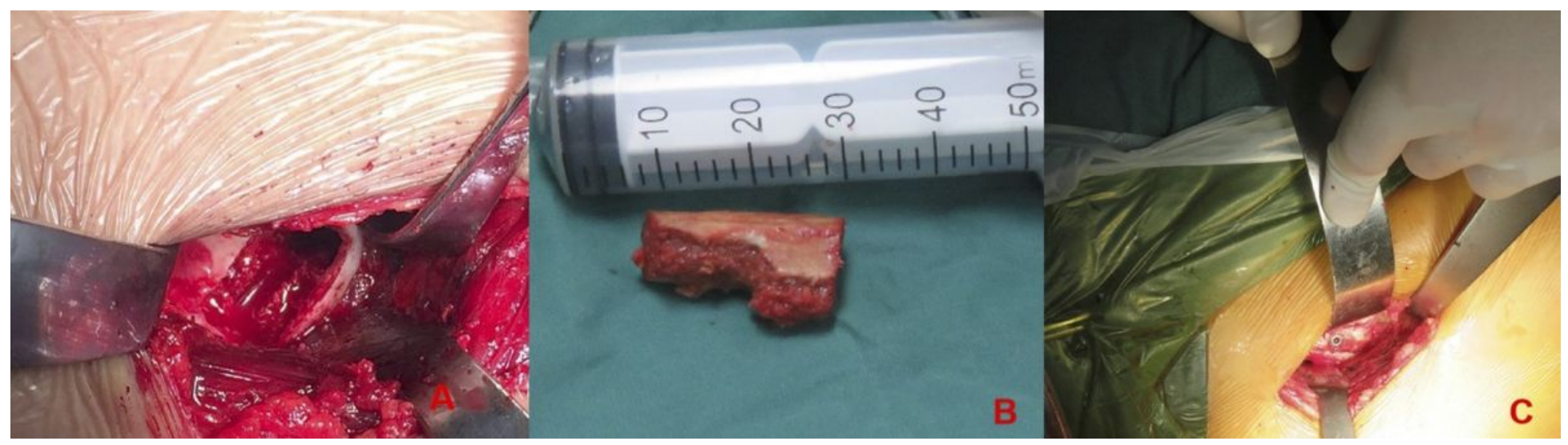

Figure 1

Bone grafting through a femoral head window. A. Exposure of the femoral head without dislocation and creation of a cortical window in the femoral head and removal of all visible necrotic bone, $B$. autogenous iliac-crest struts trimmed into its optimum shape, C. Placement of a tricortical iliac bone graft in the groove and fixation with a screw.

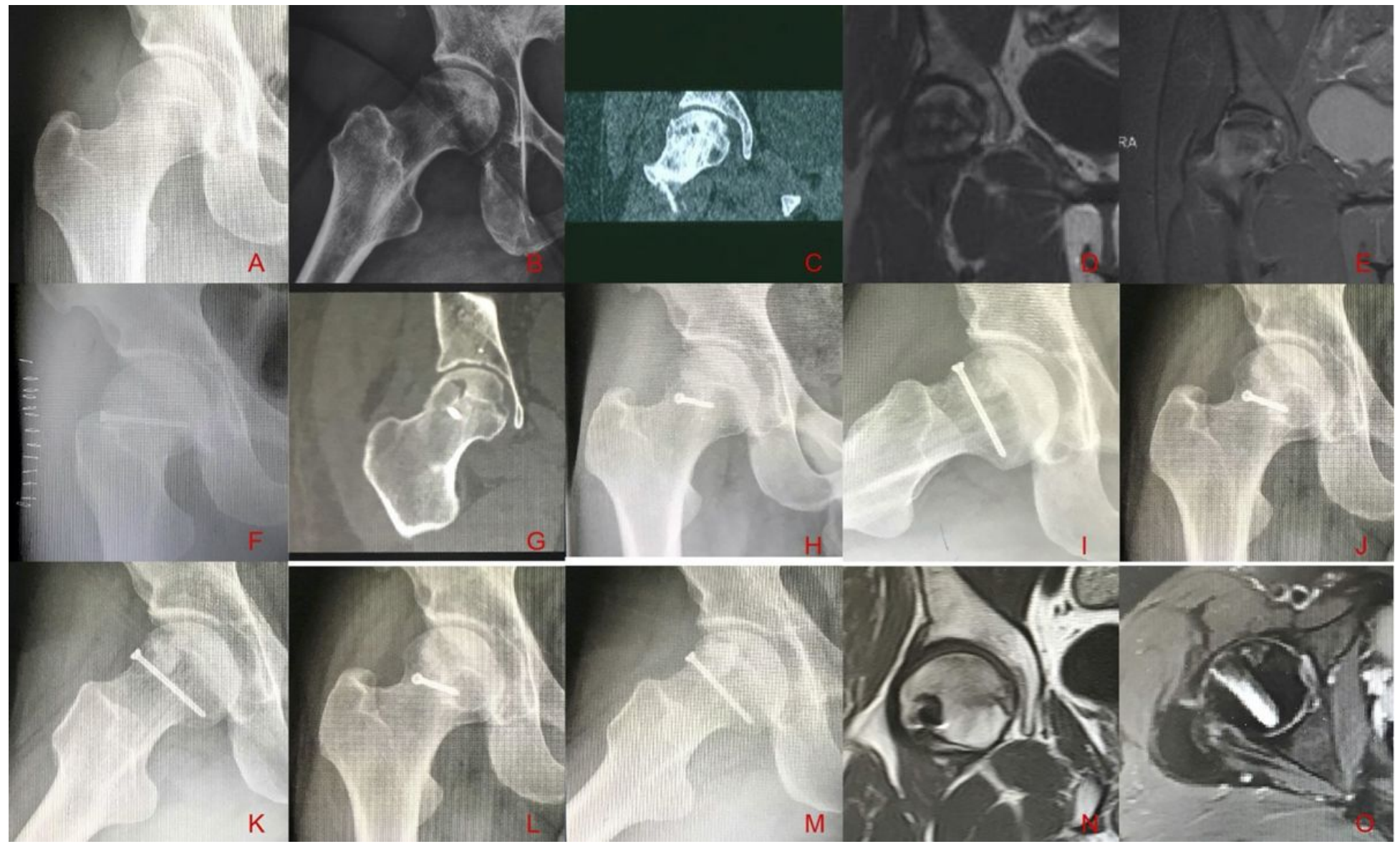

\section{Figure 2}

A 32-year-old man with osteonecrosis of the femoral head was treated with our modified trapdoor procedure. Anterior-posterior X-ray (A) and frog-position X-ray (B) show femoral head necrosis with segmental collapse. Coronal CT confirmed ONFH with collapse (C). Coronal T1(D) and STIR (E) showed 
ONFH with edema. Postoperative radiography $(F)$ showed necrotic bone that had been curetted and replaced with tricortical iliac block graft. Coronal CT (G) showed that necrotic bone had been curetted and replaced with a tricortical iliac block graft. The graft was in accordance with the contour of the femoral head. Anterior-posterior X-ray $(\mathrm{H})$ and frog-position X-ray (I) obtained 1-year post-operatively showing that the graft had healed to host bone without collapse. Anterior-posterior X-ray $(\mathrm{J})$ and frog-position $\mathrm{X}$-ray $(\mathrm{K})$ obtained 4 years post-operatively showing that the graft had healed to host bone, without collapse. Anterior-posterior X-ray $(\mathrm{L})$ and frog-position X-ray (M) obtained 8 years post-operatively show that the contour of the femoral head was intact without collapse. Coronal T1 MR images $(\mathrm{N})$ obtained 4 years post-operatively showed that the contour of the femoral head was intact, with the replacement of necrotic bone by viable bone, and normal cartilage at the femoral head. Axial STIR MR images (0) obtained 4 years post-operatively showing that the contour of the femoral head remained intact; a portion of necrotic bone has been replaced with viable bone. 